\title{
Social Protection and Informality of the Informal Sector Workers in Uganda: A Missing Link
}

\author{
Mary Baremirwe Bekoreire ${ }^{1 *}$, Edmond Maloba Were ${ }^{2}$, Pia Okeche ${ }^{2}$ \\ ${ }^{I}$ Uganda Christian University, Mbale University College, Mbale, Uganda \\ ${ }^{2}$ Kisii University, Kenya
}

*Corresponding Author: Mary Baremirwe Bekoreire, Uganda Christian University, Mbale University College, Mbale, Uganda

\begin{abstract}
The existing social protection policy excludes 93 percent of the working population of Uganda's informal sector. This study sought to establish the relationship between Uganda's social protection policy and institutionalisation of informal sector workers using the institutional approach and the Subaltern theory. Sequential mixed methods design guided the study. Data from 413 participants that included informal sector workers and government and NGO staff was collected using questionnaires, Focus Group Discussions and interviews. Multi-stage, systematic sampling and purposive sampling were used to select the study participants. Content analysis was used to analyse qualitative data whereas descriptive and inferential statistics were used to analyse quantitative data. Findings revealed a significant relationship between access to social protection and formalisation of the informal sector workers as shown by the ANOVA where $F=48.498$ and $P=0.000$; and the regression analysis of $\beta=0.350 ; p=0.000$. The study revealed that a number of workers choose to work in the black market because the gains inform of social services do not commensurate with the tax contributions. As Uganda works towards achieving access to social protection for all by 2040, informal sector workers should be categorized according to industry of operation and gender and vulnerability assessment should precede policy formation to avoid further exclusion.
\end{abstract}

Keywords: Informality, Informal Sector workers, Institutionalization, Social Protection.

\section{INTRODUCTION}

Social protection is one of the popularised global strategies of poverty reduction because it distributes resources and economic benefits to the society [1]. However, in spite of their contributions towards economic growth, informal sector workers continue to be excluded in most social protection programmes. The informal sector workers are alienated from accessing formal social protection schemes given the fact that they operate outside the formal institutional framework [2]. The informal sector workers are more vulnerable to risks and vulnerability because they dominate precarious employment and this further increases their vulnerability to fall into poverty. Women and Widows are the most vulnerable groups to risks and vulnerability because they dominate precarious employment $[3,4]$. The majority of those excluded from accessing social protection work in the agricultural sector [5].

Globally, more than $50 \%$ the world's population is employed in the informal sector whereby 80 percent of the workers in non-agricultural employment are in Asia, 65 percent in Sub-Saharan, 50 percent in Latin America and 45 percent in Middle East and North Africa [6]. The informal sector contributes significantly towards tax revenue. In Sub-Saharan Africa, the informal sector contributes to the tune of 55\% of GDP and 80\% workforce [5] and it is the avenue of $90 \%$ of the new jobs [5]. However, much as informal sector greatly contributes towards economic growth, their gains from growth do not commensurate with their contributions.

In Uganda, findings on the expansion of social protection to informal sector workers revealed that only 5 percent of the population in the informal sector is able to benefit from social insurance schemes[3]. In addition, the current government policy on social protection provides a basis for a holistic approach in addressing the risks and vulnerabilities faced by different categories of the population in the formal and informal sectors [7]. In reality however, the government programmes 
target Orphans and Vulnerable Children (OVC), People with Disabilities (PWDs), people affected by conflict and war, the elderly, youth and workers in the formal sector [7]. Also, the strategies used in poverty alleviation by the Republic of Uganda such as the Social Assistance Grant for Empowerment (SAGE) for the old people above 60 years and the Savings And Credit Cooperative Organisations (SACCOs) model are assumed to provide alternative social protection mechanisms. Practically, however, they do not directly address social protection needs of informal sector workers.

Scholars contend that administration challenges relating to informality of the sector deter the informal sector workers from accessing social protection [8,9]. The administrative challenges of social protection schemes for informal sector workers among others include irregular and seasonal nature of incomes, heterogeneous nature of the economy, unavailability of statistics and low incomes that limit the capacity of workers to contribute towards social security premiums [10]. In addition, literature also points out the significance of addressing the informality of the informal sector workers through institutionalisation to ease administration of social protection interventions $[8,11]$. Nevertheless, there is inadequate literature that explains whether access to social protection influences institutionalisation of the informal sector workers. The purpose of this study was therefore to establish the relationship between accesses to social protection informality of the informal sector in Uganda.

\subsection{Theoretical Framework}

This study was guided by the institutional framework by Lund and Srinivas and the Subaltern theory. Lund and Srinivas [12]in their institutional approach recommend establishment of stronger organisations that can represent the needs of the working poor. They argue that, an institutional framework is the first step in analysing actors in the system of social protection. It is believed that the development of institutional mechanisms promotes the voice of workers in the informal sector, while addressing structural problems of organizing workers with different employment relationships and different socio-economic interests [9]. Also, they reiterate that registration of informal workers could facilitate access to a large saving fund.

The aspects of the institutional framework as pointed out by Lund and Srinivas comprise three elements: First, they propose the need to empower poor people especially women to minimise risks and enhance regular flow of income; second, they agitate for developing different strategies for incorporating workers of different status in different ways. Lastly, they recommend a multi-sector approach to address the diversity of risks faced by the large number of workers in the informal sector. In addition, they also emphasise the need for inclusion of both the government and the private sector in programme implementation and acknowledge the role of donors in exploring the potential mainstreaming of social protection of informal workers into existing formal institutions and in building independent institutions where possible.

In consonance with the above, it can be argued that the formalisation of informal sector workers through registered institutions has high potential to foster a bottom-up and more inclusive approach, which ensures that the informal sector workers are central stakeholders in the design of social protection interventions. Consequently, this ensures equitable, accountable and transparent programmes, while cognisant of institutional capacity issues. In view of this, the state can directly implement social protection programmes or facilitate and/or promote the activities of non-state actors at multiple levels [12].

Organisation of workers in formal institutions helps to reduce the level of informality as well as increase their power of voice to advocate for better working conditions and social protection services [8]. However, this works out well only when the groups are homogeneous and are bound by shared goals and objectives. When the prerequisites of group identity - shared common problems and triggers are realised, there is a likely collective action through advocacy and bargaining with the different power holders.

Lund and Srinivas assert that the state can facilitate access and delivery of social protection through direct intervention or through facilitation role, allowing non-state participation at all levels. They also agitate for a multi-dimensional matrix approach that links together schemes for formal and informal economies in a comprehensive way. Nevertheless, the latter is seemingly too general and may not address specific social protection needs of informal sector workers such as health and education. On the other hand, the potential to develop community based social protection could be enhanced through 
horizontal linkages between NGOs, Trade Unions, government agencies, and employers $[8,13]$. There is however need to look at context-specific ways of combining contributions from different stakeholders and combining statutory and voluntary provisions [8].

The Subaltern theory is complementary to the institutional approach because it emphasizes increasing the power of voice for the oppressed and disadvantaged in advocating their rights. Ranajit Guha constituted the editorial collection of Subaltern theory authors in 1984 [14]. The subalterns refer to people who are dominated by the more powerful in a colonized society and have no voice due to their gender, race, social status, among others [15]. The Subalterns theory maintains that the voices of the oppressed and marginalized in the post-colonial societies when heard can enable the subalterns cease to be subalterns and that the subalterns should speak for themselves instead of being represented by the privileged [15]. The Subalterns and privileged should interact to ensure the representation of the Subalterns by the privileged [16].

A combination of Subaltern theory and the institutional approach helps to explain how the informal sector workers can be empowered to advocate for their social protection rights and take advantage of the patron-client relationships. The informal sector workers need the power of voice to challenge structural and systemic factors that deprive workers from accessing social protection. This study therefore proposes that, formalisation promotes the ability of the informal sector workers to have influence in the policy making process and to increase access social protection for informal sector workers.

\section{MATERials AND MethodS}

\subsection{Research Design}

This study utilised mixed methods research design because mixed methods design has the advantage of providing statistical and narrative data to facilitate greater understanding. Sequential mixed methods were used whereby data collection was done in two phases. The first phase involved collection and analysis of quantitative data collected using survey questionnaire. The questionnaires were administered to informal sector workers. The data collected were analysed and results were used to refine qualitative data collection tools that included interview guide and Focus Group discussion guides. These were later administered to government and NGO staff and informal sector workers respectively.

\subsection{Study Population and Sample Size}

The primary target of study participants were informal sector workers from Bugisu region in Eastern Uganda with membership to registered community based organisation and are actively undertaking savings and investments, among other objectives. Selection of the CBOs that participated in the study was purposively done to ensure representation across the different industries, namely; agriculture, trade, service, production and transport. The participants were specifically drawn from Mbale, Namisindwa and Manafwa Districts.

According to the District records of Mbale and Manafwa districts, at the time of study, there were 200 registered active Community Based Organisations (CBOs) with an element of savings and investment with a total membership of 5000 informal sector workers. The non-informal sector workers participants included; Government officials that directly handle social protection issues and NGO participants. The participants from the government included Head of Department for Social Protection, the Director for Social Protection and the Director of Finance and District Community Development Officers (DCDOs) from Mbale and Manafwa districts. The NGO participants were drawn from organisations that are involved in promoting labour rights at national level; and local NGOs that are working with CBOs. These included Platform for Labour Action, ILO, Uganda Social Protection Platform and Development of Research and Training and local NGOs that work with informal sector groups in Mbale and Manafwa to facilitate socio-economic development of informal sector workers. These included Child Restoration Outreach (CRO), Uganda Women Concern Ministry (UWCM), Uganda Women's Effort to Save Orphans (UWESO) and Bungokho Rural Development Centre (BRDC).

\subsection{Sample Size and Sampling Techniques}

The sample size of 400 participants was derived using Slovene's formula, [17]: 


$$
\mathrm{n}=\frac{\mathrm{N}}{1+\mathrm{Ne}^{2}}
$$

Purposive sampling was used to select the groups that participated in the study. The criteria followed in the selection of CBO included legal recognition, should have been in existence for at least three years and have renewed their membership by the end of 2017. Another criterion used was the existence of the component of savings and investment in the constitution of individual CBOs. Proportionate and stratified sampling was also used to ensure fair representation across the industries. The actual participants from the selected CBOs were finally selected using systematic random sampling. CBOs provided lists of their members which served as a sampling frame. The total membership of individual CBOs ranged from 15 to 30. There were two CBOs having large membership of up to 80 members. The average number of participants selected from individual CBOs ranged from 6 to 8, apart from the two largest CBOs where up to 20 participants were selected.

On the other hand, the participants from NGOs and the government departments were selected using purposive sampling. Selection of participants was based on the position held and ability to influence decisions in an organisation. This enabled generation of views from individuals who were both knowledgeable about the social protection policy and at the same time having ability to make significant contributions in the policy process.

\subsection{Data Collection Methods and Instruments}

Six FGDs comprising of 10- 12 people were conducted for informal sector workers. Interviews were conducted for 13 participants that included DCDOs, Director of social protection from the Ministry of Gender, Labour and Social Development (MoGLSD), Ministry of Finance (MoF) and NGOs officials working with the Community Based organisations in the area of study. Structured questionnaires with the Likert scale that ranged from 5 to 1 were used because they had ability to save time and comparison could easily be made on responses from a large sample size. Unstructured interviews were used during interviews and FGDs because FGDs allow the interviewer greater attention to ask or even change the sequence of questions in case of need [18]. In addition, conducting FGD also provided opportunity for in-depth information about the institutional and structural factors and processes that determine successful formulation and implementation of social protection policy for the informal sector.

\section{Data Analysis}

After the analysis of the quantitative data from the survey questionnaire, qualitative data were collected using FGDs with the committee representatives of the different industries to further analyse behaviours, attitudes, and priorities towards social protection. The main approach used in the analysis of data was nested analysis. Nested analysis is a unified mixed method research which combines statistical analysis of a large sample of cases with the in-depth investigation of one or more of the cases combined in a large sample [19]. Key issues of interest arising from quantitative data from members of the CBOs were followed up using qualitative methods that included focus group discussions and interviews to establish a clear description of the relationship between variables.

Data obtained using questionnaires were analysed using of both descriptive and inferential statistics. Pearson's regression analysis was used to establish the relationship between access to social protection and institutionalisation of informal sector workers in Uganda and to test the hypothesis $\left(\mathrm{H}_{1}\right)$ that, "access to social protection influences institutionalisation of informal sector workers in Uganda".

\section{FINDINGS AND DISCUSSIONS}

The vision of Uganda's social protection policy is "provision of comprehensive social protection services to address risks and vulnerabilities" [7]. This commitment is geared towards the fulfillment of vision 2040 which stipulates the importance of addressing risks and vulnerabilities with special focus on age, gender, social orientation disaster exposure and climate [20]. The questions asked were useful in explaining the extent to which social protection services are available, available and whether they are accessible to all citizens irrespective of gender, income levels, geographical location, and nature of employment among others. This paper also discusses the factors that determine access. That is, gender inclusiveness and affordability of social protection and how each of these variables influences institutionalization of the informal sector workers. 


\subsection{Availability of Social Protection Services}

The findings from the quantitative data show that organization of informal sector workers into registered Organisations workers to a small extent enables informal sector workers to access social protection such as access to health insurance, pension and other social services as reflected in Table 1 and 2 where the mean is of less and Standard Deviation (SD) are less than the scale of out of 5 in all items. This is attributed to low incomes, low savings, ignorance about social protection and lack of access to insurance schemes. The qualitative data revealed that that the average savings per individual was less than 3 USD a month. Whereas the participants across the FGDs commonly mentioned the need for grants and/or start-up capital, there were sharp variations in relation to other strategies that should be deployed by the government. For instance, those in service industry proposed the need to increase access to services such as National Social Security Fund (NSSF) and lowering the insurance fees; those from transport sector proposed the need to improve service delivery and reduce license for driving permit; while those in agriculture and produce advocated for provision of pesticides and safe food storage facilities. Given the heterogeneous nature of the sector, the Director of Social Protection recommended the need to involve various stakeholders and ensure implementation of a diversity of innovative approaches:

"There is need to develop products that are relevant to the informal economy. The players

in the provision of social protection services are tasked to think outside the box. NSSF has

been tasked to bring on board other schemes"

The study also revealed that, there are so far initiatives on paper by the government to extend social protection for the informal sector, in particular, pension and health insurance schemes. The participants from MoGLSD and MoF however said that there are no responses to shocks that target informal sector workers apart from the agricultural sector. Besides, it was found out that, much as the government through the pension bill has liberalized the insurance services and URBRA was established to regulate the activities of the private service providers, the available social protection schemes do not address the top two priority needs expressed by the informal sector participants of the study -that is loss of income and theft.

The above findings agree with previous studies that that the informal sector is broad and the precarious nature of the informal economy requires a diversity of approaches to address the specific needs of workers $[4,11]$. The schemes should be flexible enough but tailored to address the different needs of specific categories of workers [4,21]. In addition, there is need to develop social protection policies that address the different challenges of subgroups [2,22,23]. However, proponents of universal coverage argue that introducing different schemes increases fragmentation of the national social protection policy [24]. Basing on these findings, there should be a balance between universal policies such as provision of grants or low interest loans to boost workers and enable them increase income but there is also need to promote schemes that address the specific needs of individuals within and across the different sectors.

It should therefore be noted that the challenges in designing social protection interventions for the informal sector emanate from heterogeneity of the sector[23]. The recommendation to recognize the importance of interplay between contributory and noncontributory benefits and to strengthen partnerships in service provision is relevant because it would probably bridge the gap between low and high income earners[4]. Empowering the informal sector workers through skills building and provision of capital and employment increases their ability in accessing the available social protection services [25]. In consonance to these scholarly observations, the health sector in Uganda is underfunded [26[26] and the health care system is expensive, insufficient and does not meet the health needs of the population as reflected in Uganda's vision for 2040. Therefore, categorisation of workers is necessary to promote access to health insurance and the government should minimize exclusion gaps by purchasing or subsidizing premiums for low income informal sector workers.

In addition, the study also revealed that the poverty reduction strategies used by the government are generalised and they do not address the factors that lead to addressing the specific categories of social protection needs of informal sector workers As a result, the workers are caught under the trap of poverty. Hence, findings do not conform to the recommendation of inclusion of all workers through categorsation of workers in order to attend to specific risks [4].The use of the group approach could be helpful in integrating the different groups of workers who are previously [27]like the case in 
Namibia where all domestic workers that work at least half a day are by law supposed to be registered by employers so that they get membership to a social security commission [5].

\subsection{Prioritisation}

The statistical findings on institutionalization of workers revealed that, the majority of the informal sector workers do not perceive that, organization of informal sector workers into registered organizations has potential to enable the government prioritize the social insurance needs in the different sectors of employment as reflected by mean $=2.55$ and $\mathrm{SD}=1.17$. The interview data revealed that the government has not prioritized the social protection needs of registered groups. For instance, it was mentioned during the interviews with the MoGLSD staff that, there has been general representation of the informal sector by Kampala City Traders Association (KACITA) in some of the consultative meetings for Expanding the Social Protection Programme. Similarly, it was also mentioned in all the FGDs that informal sector workers are not consulted by the government to find solutions to the socio-economic risks faced by workers in specific industries. Hence, lack of representation affects the prioritisation of social protection needs across

The interview participants from the MoF and MoGLSD mentioned that the budget compels the government to prioritise infrastructural development and SCG for the elderly. This is also an indicator that, to some extent, social protection for the informal sector workers has not been prioritised and there is lack of general political will on the side of the government. Whereas Uganda has social protection legislations in place, the funds allocated to social protection are still inadequate[20]. However, lack of political commitment makes other spending priorities to overshadow spending for social protection [27]. Social protection demands the attention of policy actors in order to priorities social protection in resource allocation and consider it as a socio-economic development strategy[28].

In addition, the diverse nature of the informal economy requires a diversity of innovative approaches to address the specific risks and shocks faced by workers thereby ensuring effective interventions. This is because heterogeneity of the sector does not only lead to experiences of different shocks and risks in the lifecycle [29] but it also reveals the different levels of ability to make contributions towards insurance schemes. For instance, workers in sectors such as agriculture have seasonal income compared to trade and transport that have access to daily liquid cash through the calendar year.

Previous studies contend that the diversity risks within and across the informal sector requires specific need to recognize the importance of interplay between contributory and noncontributory benefits and to strengthen partnerships in service provision[4]. This would probably bridge the gap between low and high income earners. However, as advanced by [25], there is need to empower informal sector workers through skills building and provision of capital and employment to increase their ability in accessing the available social protection services [11].

Other scholars also contend that, the informal sector is broad and the precarious nature of the informal economy requires a diversity of approaches to address the specific needs of workers. The schemes should be flexible enough but tailored to address the different needs of specific categories of workers [21]. Those that agitate for universal coverage and argue that introducing different schemes increases fragmentation of the national social protection policy [24]. Basing on the above findings, there should be universal policies such as provision of grants or low interest loans to boost workers and enable them increase income but there is also need to promote schemes that address the specific needs of individuals within and across the different sectors.

\subsection{Equity and Gender Inclusiveness}

The findings revealed that women are moderately not excluded from accessing social insurance in comparison with their male counterparts as reflected by the mean $=3.27$ and $\mathrm{SD}=1.1$ (Table 2). In addition, it was also found out that informal sector workers are greatly excluded from accessing social protection as reflected by the mean $=2.82$ and $\mathrm{SD}=1.27$. The findings from interviews and FGDs revealed that, the existing empowerment progammes by the government such as Uganda Women Empowerment Program (UWEP) and Operation Wealth Creation that target women although they exclude certain categories of the informal sector workers. For instance, youth mentioned that they were excluded due to age. Other factors leading to exclusion are tedious process of groups' registration and ignorance about the existing opportunities. In addition, informal sector workers are 
generally excluded from accessing social protection services due to lack of awareness regarding available services and how they can be accessed; limited ability to subscribe to the available schemes.

However, much as the empowerment programmes by the government prioritise women, the interventions so far promoted by the government do not pay attention to specific risks and shocks faced by women in the lifecycle The specific risks of women in the lifecycle require increased access to maternity, child birth and old age schemes [4]. However, little attention is given to these risks by the existing schemes. The liberalization of pension scheme (as currently proposed) and universal access to health care may continue to deprive women of access to these essential services. The health delivery system in Uganda though decentralized also typified by inadequate maternal health delivery. However, issues of proximity, structural and systematic factors that deprive mothers of access to quality maternal health care for the majority of the women in Uganda [30].

Previous studies also reveal that women have structural challenges that put them at economic disadvantage. As a result, there is need for specific policies to address contextual factors that limit women from accessing social protection services. Women in the informal sector are less likely compared to men be self-employed, own account and contribute most towards household work [29]. Yet, they are at the base of economic pyramid where they are more vulnerable to risks. Women and widows in Uganda are more prone to risks and vulnerability that include working conditions, ill health including HIV/AIDS and loss of assets due to unfavorable weather [3]. In addition, majority of the women in Uganda may not be in position to make contributions towards the voluntary NSSF scheme because they are over represented in non-paid work. Thus, there is need for gender response reforms to increase coverage for risks faced by women and a gender sensitive delivery capacity [4].

The findings of this study further established that, the implementation of social protection policy is experiencing financial and technical capacity and these contribute to exclusion of some categories of workers. This study concurs with previous studies that there is need to address exclusion gaps while delivering social protection interventions. In addition the design of social protection policies and programmes should be informed by gender and poverty vulnerability analysis in order to analyze the risks of both males and female and address other cross-cutting issues such as disability, cultural barriers and gender roles at household level that limit access to social protection.

In addition, the study established that majority of the interview participants from the government view social protection as a mere approach of promoting the welfare of the beneficiaries and not as a social protection strategy. This explains the value attached in terms of budget allocation. These findings further agree with Grant [31] that social protection in Uganda is not viewed as a development strategy by most of the elites. Similarly, studies that that the elites in Uganda have negative attitudes towards social protection for the poor because they perceived that social protection is an approach that promotes dependence and "welfarism" at the expense of public resources[32] [28]. Nevertheless, there is need to devise strategies of empowering workers to overcome poverty and vulnerability. In addition, [22]the impact of a well-designed policy and appropriately funded social protection policy in terms of coverage, equality, human rights-based approach depends on the political will and allocated budget[22]. Therefore, addressing inequity and inequality gaps requires changing the mindset of those in decision making authority to enable them understand that promotion of access to social protection does not only lead to increased realization of human rights but it is also an essential ingredient in poverty reduction.

\subsection{Affordability of Social Protection Services}

The study revealed that the informal sector workers lack adequate capacity to access social formal social protection. As reflected in Table 2, those who indicated that they can afford to access social insurance from private service providers were reflected by a mean $=2.55$ and $\mathrm{SD}=1.26$. Additionally, majority indicated that they have not accumulated savings to enable them overcome economic hardship (mean=2.06, $\mathrm{SD}=1.05$ ). It was further mentioned that during the FGDs that, low incomes coupled with high level of dependence and high interests on loans limit their ability to save and contribute towards an insurance scheme. One of participants from Trade FGD said:

"Joining insurance requires money and yet we depend on loans. We earn little and can't save for insurance. What we get as profit is very little" 
The aspect of high level of poverty as a result of low incomes was more pronounced among the interview participant to be a key factor deterring informal sector from accessing social insurance services. It was also pointed that the insurance services are expensive and they are not easily affordable by most of the informal sector workers. One of the participants pointed out that:

"The challenge is low incomes of poor people vis-à-vis money required for services...To get good health services requires a lot of money which cannot be easily affordable by majority of the informal sector workers" (NGO participant).

Another participant said:

"...Also their incomes are low. Someone may be saving between Ug Shs. 1000-2000/=

(USD 0.28-0.56) per month and this leads to inadequate insurance cover" (NGO participant)

These findings contend with the previous studies that majority of the informal sector workers have limited incomes and as a result, they are not in position to access social protection services from private service providers.) Household poverty is a major determinant of the increasing household heads in wage employment in the informal sector [33]. Limited capital for investment compels most of the workers to operate on a marginal scale [34]. Consequently, low incomes make it difficult for most of them to make contributions towards social protection schemes [35]. Pooling resources would be pertinent in promoting access to social protection schemes [36] but this is limited by the hostile economic environment that limits savings and investments.

Scholarly literature recommends that, the state should intervene to provide social protection services to the poor population to address the challenges relating to affordability. The proposed strategies include; non-contributory health care which has for instance has proved to be successful in Thailand [37], universal health insurance cover for informal sector workers [24] and empowerment of informal sector workers through training and increased ability to advocate for social protection services [2].

It was also reported that, there are budget constraints in funding social protection interventions and this limits the government's capacity to implement social protection programmes for the diversity of workers in the informal sector. This concurs with [20] who reported that, there are limited financial allocations for social protection and lack of harmonized commitment by the government to roll out cash transfers for SCG for the elderly.

\subsection{Effect of Access to Social Protection on Institutionalisation of Informal Sector Workers in Uganda}

The $\mathrm{R}^{2}$ results of 0.122 in the regression analysis in (Table 3) indicate that the overall variance in the institutionalization of the informal sector explained by access to social protection is $12.2 \%$. This means that informal sector workers' access to the social protection policy has a significant effect on the institutionalization of the informal sector. Thus, the hypothesis that "aaccess to social protection has a positive influence on institutionalisation of informal sector workers" is accepted.

There is a significant relationship between access to social protection and institutionalization of the informal sector workers in Uganda as shown by the ANOVA where $\mathrm{F}=48.498$ and $\mathrm{P}=0.000$ and the regression analysis of $\beta=0.350 ; \mathrm{p}=0.000$ (see Table 4 and 5).This implies that access to social protection has a significant influence on the institutionalization of the informal sector workers. The informal sector workers are pushed to have membership in CBOs in order to pool resources. This enables individuals to start/ boost their businesses and support one another financially whenever there are incidentals, particularly death.

The findings also revealed that lack of tangible incentives discourages institutionalisation of informal sector workers in Uganda. Whereas the government is eager to tax the workers, the benefits that that accompany registration are hardly feasible. Thus, to a larger extent, registration has not brought significant benefits to the members of the $\mathrm{CBO}$ and this explains why many community organisations operate informally. These findings are not in conformity with previous studies that informal sector workers prefer remain informal in order to avoid paying taxes[38][34]. On the contrary, it implies that availability of social protection services through institutionalisation would be a good motivator for majority of the informal sector workers to institutionalise and even pay taxes. In addition, the findings 
suggest that, the informal sector avoid paying taxes because the benefits from taxations do not commensurate to the amount paid through taxation.

Furthermore, the results of the study conducted in 41 developing countries revealed that, informalisation of workers in the informal sector increases with lack of protection from poverty[39]. In consonance with these results, it is argued that, for informal sector to formalise, they need to be security of their livelihood. Informal sector workers opt to remain informal due to lack of economic security. Economic security can be enhanced by conducting initial negotiations of labour standards and benefits with the informal sector workers to inform the formulation of social protection policy[40]. Hence, these findings suggest that the government should design polices that focus on addressing the identified drivers to informalisation by including incentives encourage institutionalization of workers. Such incentives should include but not be limited to increased access to grants opportunities, ability to negotiate for opportunities and social services and access to social protection, among others.

Findings also show that there are limited opportunities in terms of social services as a result of membership to a CBO. It was found out that a number of groups have not benefited from government grants and this discourages them from registering their organisations. This agrees with the others scholars that there is need to ensure that public policies emphasize socio-economic benefits[41]. social protection is a public right that should be accessed by informal sector workers [42]. Increased access to social protection services in this case provides a mechanism of enabling informal sector workers to benefit from tax revenue. As a result, a significant number of workers will cease to operate under the black market. In South Africa and Brazil, a quarter of domestic workers are considered formal because the employers contribute old age pension. In both South Africa and Brazil, domestic workers have identity cards that entitle them to various benefits [43]. This necessitates the need to negotiate for labour standards and benefits with employees [34] and to discuss risks, needs and rights with employers [9].Similarly, in Namibia, employers were required to register domestic workers who work at least one day a week so that they can be affiliated with social security commission including maternity protection [4].

Scholarly literature discusses a number of strategies that are essential in encouraging informal sector workers to register and consequently improve the infrastructure in the work place. These include among others include; the need to strategically offer direct incentives to informal sector workers who formalize such as protection from occupational hazards, access to training opportunities, unionization and representation of other workers in national meetings[40], to mention but a few. There is also need to promote and/or design formalisation policies to enhance benefits that include access to technology, promotion of cross-border trade and improving the infrastructure in the workplace [35].

\section{CONCLUSION}

There is a significant relationship between access to social protection and institutionalisation of the informal sector workers in Uganda. The informal sector workers are motivated to have membership in CBOs in order to pool resources. This enables individuals to start/ boost their businesses and support one another financially whenever there are incidentals, particularly death. However, there are no deliberate efforts by the government to empower the workers to harness the benefits of institutionalisation. In addition, majority of the informal sector workers do not have the capacity access to formal social protection schemes due to number of factors. The major ones include lack of reasonable income to enable them make regular contributions and unfavorable social protection policy that does not promote categorisation and targeting of workers. It is expected that categorisation of workers should lead to addressing of the specific needs of workers, thus institutionalisation. However, as a result as of lack of categorisation, vulnerable groups such as youth and women continue to be deprived of access to social services. This is partly because the strategies used that include universal health coverage and voluntary contributions to micro-insurance schemes which do not compel the workers to institutionalise. In addition, inability to access a social protection schemes automatically leads to informality (non- institutionaation) of workers because a number of workers choose to work in the black market in order to avoid paying taxes since there are no tangible benefits that commensurate with the taxes charged.

Finally, realising Uganda's vision 2040 requires deliberate effort on the side of the government. For instance, needs assessment should precede formulation of social protection strategy for informal 
sector workers. In addition, an effective and sustainable social protection policy for informal sector workers should entail empowerment of workers to identify their specific risks and contribute solutions towards addressing them. In addition, there is need to design interventions that fit the diversity of different categories of workers in the informal sector. Finally, the informal sector workers should be actively engaged during the entire policy process to harness the benefits of relevance, affordability, ownership and sustainability of schemes.

\section{REFERENCES}

[1] Babajanian, B. and J. Hagen-Zanker, J. How do social protection and labour programmes contribute to social inclusion? Evidence from Afghanistan, Bangladesh, India and Nepal, Background Note. London: ODI (2012).

[2] S. W. Handayani and Asian Development Bank, editors, Social Protection for Informal Workers in Asia (Asian Development Bank, Mandaluyong City, Metro Manila, Philippines, 2016).

[3] C de Paz M, W. and J- J. Barya, J,J., Expanding Social Protection to informal Sector in Uganda, Ministy of Gender, Labour and Social Development (2014).

[4] Holmes, R. and Scott,L., Extending Social Insurance to Informal Workers, ODI Working Paper April 2016, London 49 (2016).

[5] ILO, Statistical update on employment in the informal economy - June 2012, (2012). Reteieved from http://www.ilo.org/global/statistics-and-databases/WCMS_182504/lang--en/index.htm

[6] J. Vanek, M. A. Chen, F. Carré, J. Heintz, and R. Hussmanns, Women in Informal Employment: Globalizing and Organizing (WIEGO) Working Paper (Statistics) 2, 47 (2014).

[7] Republic of Uganda. The Uganda National Social Protection Policy, Ministry of Gender, Labour and social Development (MGLSD (2015).

[8] F. Lund, Promoting Pro-Poor Growth: Social Protection, Paris, OECD (2009).

[9] D. Hulme and A. Barrientos, Social Protection for the Poor and the Poorest: Concepts, Policies and Politics (Palgrave MacMillan, 2010).

[10] E. T. Gonzalez and R. G. Manasan, Social protection in the philippines . In Social Protection in Southeast \& East Asia, Friedrich Elbert Stiffung, Singapore pp 131-230 (2002).

[11] Bekoreire, M, B., Were, E,M and Okeche, P., Institutionalizing the Informal Sector Through Social Protection Policy in Uganda. Journal of Popular Education in Africa. 2(3), 56 - 65 (2018).

[12] Lund, F,J and S. Srinivas,S., Learning from Experience: A Gendered Approach to Social Protection for Workers in the Informal Economy. International Labour Organization (2000).

[13] A. Barrientos and S. W. Barrientos, Extending Social Protection to Informal Workers in the Horticulture Global Value Chain .Social protection discussion paper, 2002).

[14] Chakrabarty, D, Subaltern Studies and Postcolonial Historiography. Nepantla: Views from South, 1(1), pp 9-32 (2000).

[15] B. Binebai, Voice Construction in the Postcolonial Text: Spivakian Subaltern Theory in Nigerian Drama 9, 206 (2015).

[16] G. C. Spivak, Can the Subaltern Speak? Reflections on the History of an Idea 21 (1988).

[17] M. E. Amin, Social Science Research: Conception, Methodology and Analysis (Makerere University, 2005).

[18] C. R. Kothari, Research Methodology: Methods and Techniques, Second Revised Edition .New age International Publishers, New Delhi (2004).

[19] Lieberman, E, S. Nested analysis as a mixed method Strategy for Comparative Research. American Political Science Review 99, 435 (2005).

[20] M. Guloba, S. Ssewanyana, and E. Birabwa, A Pathway to Social Protection Development in Uganda: A Synthesis Report (2017).

[21] RNSF. Extending coverage: Social protection and the informal economy. Experiences and ideas from researchers and practitioners. Research, Network and Support Facility, ARS Progetti, Rome; Lattanzio Advisory, Milan; and AGRER, Brussels. (2017).

[22] M. Meißner, in (Deutsche Gesellschaft für Internationale Zusammenarbeit (GIZ) GmbH, DagHammarskjöld-Weg 1-5 65760 Eschborn/ Germany, 2014).

[23] S. Michael and K. Kaleigh, in Social Protection for Infomral Workers in Asia, Asian Development Bank, Asia, 2016), pp. 9-62.

[24] C. Michael and C. David, in Social Protection for Informal Workers in Asia (Asian Development Bank, Asia, 2016), pp. 82-131. 
[25] D. A. Robalino, D, A., Rawlings, L and Walker, I., Building Social protection and Labour systems: Concepts and Operational Implications. Background Paper for World Bank 2012-2022. Discussion Paper No. 1202 (2012).

[26] Solidar, Social Protection Monitoring Country Report - Uganda (2016).

[27] Getu, M and Devereux, S., Informal and Formal Social Protection Systems in Sub-Saharan Africa, Fountain Publishers, Kampala. (2013)

[28] C. Lwanga-Natle, C., Namuddu, J. and P. Onapa, Social Protection in Uganda: A call for action. Development Research and Training. Discussion Paper 1 (2008).

[29] Partnership for Economic Policy (PEP), Providing Social Protection to the Informal Sector, Research Notes No. 1. (2013).

[30] M. Bekoreire B. and M. Nangoli, in Africa and Challenges of Gobalization: Opportunities and Prospects. (Catholic University of East Africa (CUEA), 2014), pp. 172-183.

[31] Grant, U. Research into Policy Processes: Bringing Global Evidence on Social Protection into Local Policy Contexts. Background Paper for the Chronic Poverty report. Overseas Development Institute (2006).

[32] Lavers, T and Hickey, S. Investigating the Political Economy of Social Protection Expansion in Afric: At the Intersection of Transnational Ideas and Domestic Politics. EISID Working Paper No. 47 (2015).

[33] Amuedo-Dorantes, C. Determinants of poverty implications for informal sector work in Chile. Economic Development and Cultural Change 52, 347 (2004).

[34] M. A. Chen, R. Jhabvala, and F. Lund, Supporting Workers in the Informal Economy: A Poilcy Framework. A Paper Prepared for ILO Task Force on the Informal Economy (2001).

[35] E. Stuart, E. Samman, and A. Hunt, Improving the Lives of Workers at Risk of Being Left behind. London: Overseas Development Institute (2018).

[36] B. M. Muiya and A. Kamau, Universal Health Care in Kenya: Opportunities and Challenges for the Informal Sector Workers (2013).

[37] Samson and Kenny, in Social Protection for Informal Sector Workers in Asia. Asian Development Bank, (2016).

[38] R. B. Freeman, in Handbook of Development Economics (Elsevier, 2010), pp. 4657-4702.

[39] C. C. Williams, Tackling Enterprises Operating in the Informal Sector in Developing and Transition Economies: A Critical Evaluation of the Neo-Liberal Policy Approach 4, 9 (2014).

[40] M. A. Chen, The Informal Economy: Definitions, Theories and Policies (WIEGO working Paper, 2012).

[41] Williams, C, C., Evaluating the Variations in Employment Relations Across Developing! Economies: A Degrees of Informalisation Approach. Journal of Economy and its Applications 5, 1pp 1-21 (2015).

[42] M. Chen, C. Bonner, M. Chetty, L. Fernandez, K. Pape, F. Parra, A. Singh, and C. Skinner, 65 (2013).

[43] ILO. Women and Men in the Informal Economy: A Statistical Picture, ILO, Geneva, Third Edition (2014).

\section{APPENDEX}

Table1: Institutionalization of the informal sector

\begin{tabular}{|c|c|c|c|c|c|c|c|c|c|c|c|c|}
\hline \multirow[t]{2}{*}{ Item } & \multicolumn{2}{|c|}{ SD } & \multicolumn{2}{|r|}{ D } & \multicolumn{2}{|c|}{ NS } & \multicolumn{2}{|c|}{$\mathbf{A}$} & \multicolumn{2}{|c|}{$\mathbf{S A}$} & \multirow[b]{2}{*}{ Mean } & \multirow[b]{2}{*}{ SD } \\
\hline & $\mathrm{F}$ & $\%$ & $\mathrm{~F}$ & $\%$ & $F$ & $\%$ & $F$ & $\%$ & $\mathrm{~F}$ & $\%$ & & \\
\hline $\begin{array}{l}\text { Organisation of informal sector workers into } \\
\text { registered organisations builds workers' } \\
\text { capacity to demand for social services from } \\
\text { the government }\end{array}$ & 4 & 1.1 & 41 & 11.7 & 22 & 6.3 & 228 & 65.1 & 55 & 15.7 & 3.83 & 0.874 \\
\hline $\begin{array}{l}\text { Informal sector workers are likely to register } \\
\text { their businesses if there are economic gains } \\
\text { associated with registration }\end{array}$ & 35 & 10.0 & 35 & 10.0 & 29 & 8.3 & 199 & 56.9 & 43 & 12.3 & 3.49 & 1.16 \\
\hline $\begin{array}{l}\text { Many informal sector workers are likely to } \\
\text { pay taxes if there are feasible gains } \\
\text { accompanying taxation }\end{array}$ & 9 & 2.6 & 59 & 16.9 & 45 & 12.9 & 188 & \begin{tabular}{|l|}
53.7 \\
\end{tabular} & 49 & 14.0 & 3.60 & \begin{tabular}{|l|}
1.00 \\
\end{tabular} \\
\hline $\begin{array}{l}\text { Availability of social insurance by } \\
\text { government/NGOs can be a good motivator } \\
\text { for many informal sector workers to come } \\
\text { out of the black market }\end{array}$ & 58 & 16.6 & 49 & 14.0 & 29 & 8.3 & 167 & 47.7 & 47 & 13.4 & 3.27 & 1.32 \\
\hline $\begin{array}{l}\text { Registered business in Uganda are more } \\
\text { likely to access cash/in-kind support from } \\
\text { the government }\end{array}$ & 31 & 8.9 & 33 & 9.4 & 37 & 10.6 & 203 & 58.0 & 46 & 13.1 & 3.57 & 1.11 \\
\hline
\end{tabular}




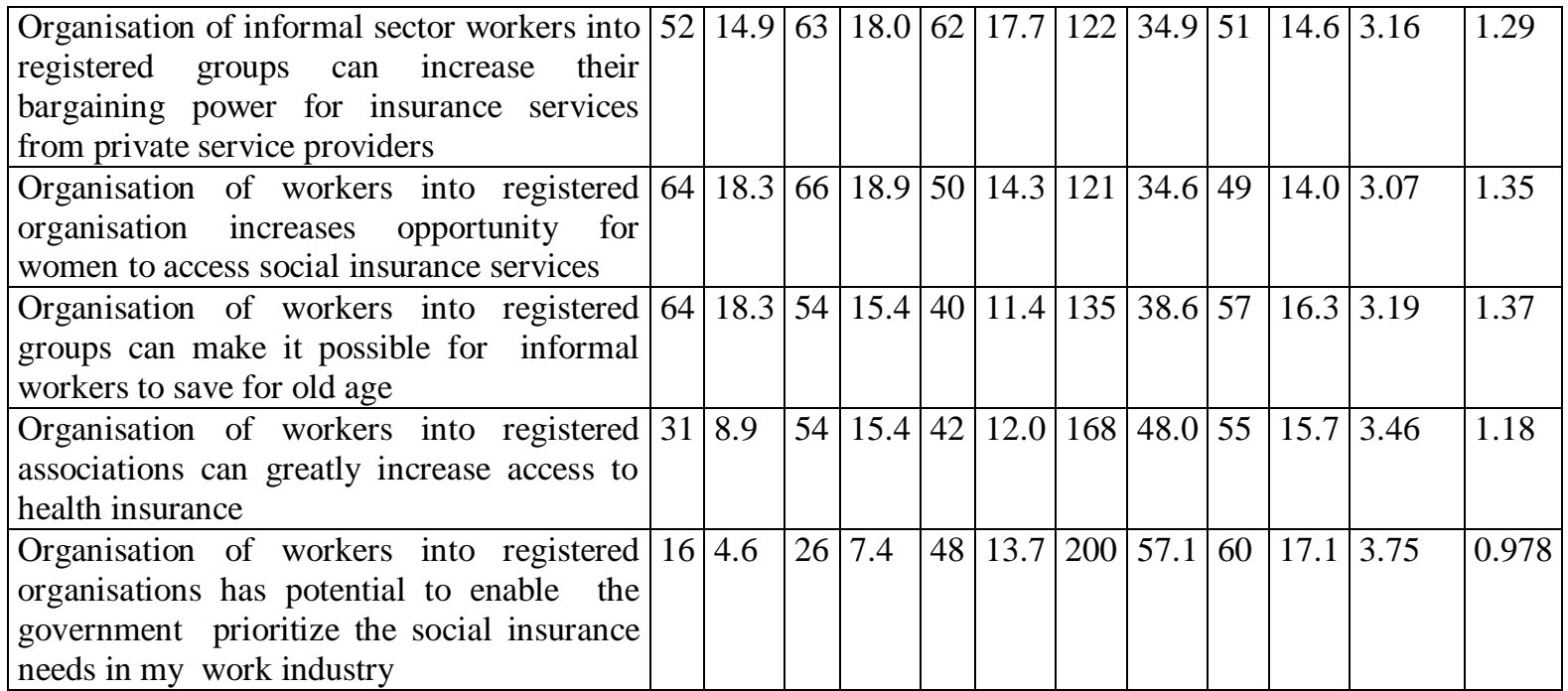

Table2: Descriptive statistics on access to social protection institutionalization of informal sector workers

\begin{tabular}{|c|c|c|c|c|c|c|c|c|c|c|c|c|}
\hline \multirow[t]{2}{*}{ Item } & \multicolumn{2}{|c|}{ SD } & \multicolumn{2}{|c|}{ D } & \multicolumn{2}{|c|}{$\mathbf{N S}$} & \multicolumn{2}{|c|}{$\mathbf{A}$} & \multicolumn{2}{|c|}{$\mathbf{S A}$} & \multirow[b]{2}{*}{ Mean } & \multirow[b]{2}{*}{ SD } \\
\hline & $\mathrm{F}$ & $\%$ & $\mathrm{~F}$ & $\%$ & $\mathrm{~F}$ & $\%$ & $\mathrm{~F}$ & $\%$ & $\mathrm{~F}$ & $\%$ & & \\
\hline $\begin{array}{l}\text { The social protection policy in } \\
\text { Uganda does not exclude majority } \\
\text { women from accessing social } \\
\text { insurance in equal measure }\end{array}$ & 17 & 4.9 & 89 & 25.4 & 83 & 23.7 & 104 & 29.7 & 57 & 16.3 & 3.27 & 1.15 \\
\hline $\begin{array}{l}\text { Workers in the informal sector find } \\
\text { it easy to access health insurance. }\end{array}$ & 67 & 19.1 & 91 & 26.0 & 60 & 17.1 & 102 & 29.1 & 30 & 8.6 & 2.82 & \begin{tabular}{|l}
1.27 \\
\end{tabular} \\
\hline $\begin{array}{l}\text { Informal sector workers can afford } \\
\text { to pay for insurance } \\
\text { provided by private } \\
\text { providers }\end{array}$ & 90 & 25.7 & 106 & 30.3 & 39 & 11.1 & 100 & 28.6 & 15 & 4.3 & 2.55 & 1.26 \\
\hline $\begin{array}{l}\text { My specific insurance needs are } \\
\text { prioritized by the existing social } \\
\text { protection strategies }\end{array}$ & 81 & 23.1 & 97 & 27.7 & 84 & 24.0 & 74 & 21.1 & 14 & 4.0 & 2.55 & 1.17 \\
\hline $\begin{array}{l}\text { Informal sector workers have easy } \\
\text { access to pension scheme }\end{array}$ & \begin{tabular}{|l|}
108 \\
\end{tabular} & 30.9 & 115 & 32.9 & 69 & 19.7 & 43 & 12.3 & 15 & 4.3 & 2.26 & 1.14 \\
\hline $\begin{array}{l}\text { In case of unforeseen } \\
\text { circumstances such disability, } \\
\text { illness or loss of employment, I can } \\
\text { easily access some kind of social } \\
\text { assistance from the government }\end{array}$ & 120 & 34.3 & 102 & 29.1 & 31 & 8.9 & 87 & 24.9 & 10 & 2.9 & 2.33 & 1.25 \\
\hline $\begin{array}{l}\text { I have accumulated reasonable } \\
\text { savings that can help me or my } \\
\text { household in case of economic } \\
\text { hardships }\end{array}$ & 121 & 34.6 & 142 & 40.6 & 42 & 12.0 & 36 & 10.3 & 9 & 2.6 & 2.06 & 1.05 \\
\hline
\end{tabular}

Source: Primary Data 2017

Table3: Model Summary

\begin{tabular}{|l|l|l|l|l|}
\hline Model & R & R Square & Adjusted R Square & Std. Error of the Estimate \\
\hline 1 & $.350^{\mathrm{a}}$ & .122 & .120 & .74444 \\
\hline
\end{tabular}

Table4: ANOVA

\begin{tabular}{|l|l|l|l|l|l|l|}
\hline \multicolumn{2}{|l|}{ Model } & Sum of Squares & Df & Mean Square & F & Sig. \\
\hline \multirow{4}{*}{1} & Regression & 26.877 & 1 & 26.877 & 48.498 & $.000^{\text {a }}$ \\
\cline { 2 - 8 } & Residual & 192.859 & 348 & .554 & & \\
\cline { 2 - 7 } & Total & 219.736 & 349 & & \\
\hline
\end{tabular}

Table5: Coefficients ${ }^{a}$

\begin{tabular}{|l|l|l|l|l|}
\hline Model & Unstandardized Coefficients & $\begin{array}{l}\text { Standardized } \\
\text { Coefficients }\end{array}$ & $\mathrm{t}$ & Sig. \\
\hline
\end{tabular}


Social Protection and Informality of the Informal Sector Workers in Uganda: A Missing Link

\begin{tabular}{|l|l|l|l|l|l|l|}
\hline \multicolumn{2}{|l|}{} & B & Std. Error & Beta & & \\
\hline \multirow{2}{*}{1} & (Constant) & 2.416 & .152 & & 15.872 & .000 \\
\cline { 2 - 7 } & access to social protection & .401 & .058 & .350 & 6.964 & .000 \\
\hline
\end{tabular}

Citation: Mary Baremirwe Bekoreire, et.al. "Social Protection and Informality of the Informal Sector Workers in Uganda: A Missing Link” International Journal of Political Science (IJPS), vol 5, no.3, 2019, pp. 1-13. doi: http://dx.doi.org/ 10.20431/2454-9452.0503001.

Copyright: (C) 2019 Authors. This is an open-access article distributed under the terms of the Creative Commons Attribution License, which permits unrestricted use, distribution, and reproduction in any medium, provided the original author and source are credited. 